\title{
PASADO Y PRESENTE DE LAS ALGUERAS DE COLIUMO Y COCHOLGÜE. UNA DESCRIPCIÓN DE LA RELACIÓN ENTRE GÉNERO, ECONOMÍA E IDENTIDAD
}

\author{
Past and present of the algueras of Coliumo and Cocholgüe. A description \\ of the relationship between gender, economy and identity
}

\section{CARLA DONOSO, CONSTANZA MOLINA HIDALGO, DIEGO VALDÉS VIVANCO E ISABEL ORTIZ ASTETE*}

Fecha de recepción: 30 de noviembre de 2015- Fecha de aprobación: 28 de marzo de 2016

\section{Resumen}

En este artículo resumimos y exponemos los hallazgos de una investigación cuyo objetivo fue indagar en los saberes y labores ligadas a actividades productivas del borde costero, realizadas por mujeres y su relación con la configuración de identidades locales en las caletas de Cocholgüe y Coliumo -Región del Bio-Bío, Chile- durante el año 2015. A través del método etnográfico se realizó el acercamiento a la comunidad de mujeres de ambas localidades. Este estudio da cuenta de un contexto de transformación, marcado por una fuerte crisis en la explotación de los recursos marinos que lleva al abandono de las actividades tradicionales de recolección de algas y mariscos. Este cambio es vivido con tensión por parte de las mujeres quienes se sienten vinculadas fuertemente al mar. Sin embargo, el deterioro de su salud y de sus condiciones de vida las obliga a buscar nuevos horizontes. En este escenario, las posibilidades de desarrollo turístico de ambas caletas y algunos proyectos productivos, son vistas como una oportunidad para las mujeres.

Palabras clave: algueras, Coliumo, Cocholgüe, género, identidad.

\begin{abstract}
In this paper, we account for the main findings of a research project which main goal was to describe the popular knowledge and economic activities of women from the seacoast, and their relationship with local cultural identities in Cocholgüe and Coliumo -Bio-Bío region, Chile- in 2015. Through the ethnographic method, we got closer to women's organizations in both settings. The research findings account for a changing context featured by a strong ecological crisis that affects the sea resource exploitation, and makes inhabitants in both settings look for new sources of income. Women are developing new economic activities as they slowly leave behind their traditional activities of collecting seafood and seaweed. Women experienced this change with contradictions, because they still feel strongly attached to the sea. However, their health issues (related to their work at the seacoast) and diminishing life conditions force them to look for new horizons. In this changing scenario, the chances of developing tourism-related businesses in Cocholgüe and Coliumo as well as the new economic projects, in which women are involved, are seen by them as opportunities for a better future.
\end{abstract}

Keywords: algueras, Coliumo, Cocholgüe, gender, identity.

\footnotetext{
* Antropólogos de la Universidad de Concepción. Equipo de investigación adscrito al Programa Multidisciplinario de Estudios de Género (PROMEG) de la Universidad de Concepción, Chile. Correo-e: cadonos76@gmail.com
} 


\section{Introducción ${ }^{1}$}

A continuación daremos cuenta de los hallazgos centrales de un estudio etnográfico realizado en las caletas de Coliumo y Cocholgüe, localizadas en la Región del Bio-bío, Chile. El objetivo de este proyecto fue indagar en los saberes y labores ligadas a actividades productivas del borde costero, realizadas por mujeres y su relación con la configuración de identidades locales en las caletas de Cocholgüe y Coliumo durante el año 2015. El trabajo de etnografía se realizó entre los meses de junio y noviembre de 2015 y consideró diversas actividades tales como reuniones y entrevistas grupales, acompañamiento de las mujeres en sus actividades diarias, entrevistas casuales y entrevistas en profundidad (se realizaron 14 entrevistas grabadas a algueras de ambas localidades), y la participación en algunas actividades de los sindicatos de algueras de Cocholgüe y el sindicato № 1 de Coliumo. Además, se realizó un taller de fotografía en ambas localidades a fin de que las participantes realizaran un registro fotográfico de su localidad, relevando aquellas imágenes que les parecían significativas.

Respecto a las características geográficas de los lugares estudiados, Cocholgüe es una cala (pequeño orificio costero más pequeño que una bahía) ubicada entre las coordenadas 36 35'15" sur y 72 58'60" oeste; a una distancia de 3,6 km. aproximados al norte de la comuna de Tomé. Cocholgüe es conocida como la caleta de captura de merluza (Merlucciusgayigayi) más grande del país y reconocida a nivel regional por sus atractivos turísticos y gastronómicos. Otra de sus características es la presencia de fósiles en sus costas, en donde incluso se han encontrado restos de animales prehistóricos, por lo que es una zona de interés científico. Cocholgüe se divide en dos sectores. La Caleta Chica donde se ubican los restaurantes, cabañas y casas de veraneo y la Caleta Grande que es donde habitan las familias de pescadores y algueras, y donde se realizan las actividades económicas ligadas al borde costero: pesca, recolección, buceo, etc. En la parte alta de Cocholgüe se encuentra la población Nueva Cocholgüe y la Villa Cocholgüe.

La caleta de Cocholgüe en la actualidad está viviendo un proceso de cambio que se inicia el año 2005, con la relocalización de familias de la caleta por parte del Estado chileno debido a una amenaza de remoción en masa en las laderas de los cerros habitados en la Caleta Grande. En ese momento se toma la decisión de instalar un campamento provisorio en la parte alta de Cocholgüe donde actualmente se ubica una de sus escuelas. El terremoto y tsunami del 27 de febrero del 2010, provocó que cientos de familias evacuaran la caleta y se instalaran espontáneamente en una cancha en la zona alta de la caleta. Esta ocupación temporal duró hasta el año 2011, año en el que el Estado hace entrega de la población Nueva Cocholgüe donde habita hoy en día gran parte de la comunidad. La Caleta Grande, antiguo lugar de residencia de muchos en la actualidad está casi desocupada. Si bien hay familias que se quedaron viviendo allí, la mayoría le da un uso esporádico a las viviendas, las arriendan en el verano, algunas están en venta o las ocupan como bodega para sus implementos de pesca.

Por parte de algunas habitantes de Cocholgüe existe una sensación de olvido o desconocimiento de la caleta. En el primer encuentro que tuvimos una de ellas nos comentó: "Cocholgüe no sale en el mapa". Luego del terremoto del 2010 pudieron constatar en los medios de comunicación que la caleta no es conocida a nivel nacional, en los mismos medios se informaba sobre la situación de las caletas vecinas, Dichato 
y Coliumo, y en menor medida de Cocholgüe. Este sentimiento de "invisibilización" se declaró en más de un encuentro con las algueras.

Por su parte Coliumo, es una península que configura el borde oeste de la Bahía de Dichato, está ubicada a 10 kilómetros al norte de Tomé y su nombre en chedungun significa "agua de poleo". Sus coordenadas geográficas son 36" 31' 38, 96" sur y 72" 57 ' 26. 61" oeste (ubicación a los Morros de Coliumo como punto de referencia). Se caracteriza por estar divida en tres sectores separados por accidentes geográficos, entre los cuales se destacan sus tres asentamientos principales conocidos como "Las Vegas de Coliumo", "Caleta del Medio" y "Los Morros". La caleta propiamente tal se formó entre 1915 y 1920, ya que la actividad pesquera inicial era solo para autoconsumo (Intendencia Bio-Bío, 2010). Según el Censo 2002, se registran 901 habitantes. En sus características de emplazamiento se destaca como un extremo de bahía, con aguas tranquilas y frías, aptas para la pesca artesanal y el cultivo y extracción de mariscos, y una actividad secundaria de agricultura y ganadería.

En los relatos de las mujeres se evidencian con mucho detalle las nefastas consecuencias que tuvo el terremoto de 2010 en Coliumo, que implicó no solo la destrucción de sus viviendas y materiales e implementos de trabajo, sino que también alteró por completo el ecosistema del cuál ellas obtenían su subsistencia, lo que tuvo considerables repercusiones económicas para ellas y sus familias. Así, las entrevistadas señalan como una de las consecuencias del terremoto una fuerte crisis en la disponibilidad de recursos marinos, lo que tuvo efectos directos en sus ingresos económicos. Asimismo, muchas de las entrevistadas que residían en el borde costero antes del terremoto, se trasladaron a sectores ubicados hacia el interior, lo que tuvo un impacto directo en su modo de vida.

Así, en la localidad de Coliumo la producción de recursos y suelo marino fue mayormente dañado durante este evento, debido a que el mar se comportó de manera más violenta en este sector arrasando la mayor parte de las embarcaciones y viviendas situadas en el borde costero, a diferencia de Cocholgüe donde el maremoto no logró arrasar con las casas pero sí con muchos botes de pesca y herramientas de trabajo, esto debido en parte según los habitantes, a la formación geográfica de Cocholgüe que contuvo la fuerza de la mar.

\section{Pasado y actividades productivas}

Tanto en el caso de Cocholgüe como el Coliumo, el pasado de la caleta se recuerda como un paraíso de abundancia. Los recursos estaban a disposición de los habitantes de manera generosa, la alimentación daba cuenta de eso. En una de las entrevistas realizadas se describieron los platos que hace décadas se preparaban: el congrio, las empanadas y caldillos aparecen como platos de preparación diaria.

Otro elemento del pasado de la Caleta de Cocholgüe que se recuerda con nostalgia, son las múltiples festividades que se realizaban, tales como la celebración del Día de la Raza, las Fiestas Patrias, la semana cocholguana, San Pedro y San Pablo, las carreras de natación en la playa, etc. Si bien en la actualidad algunas de ellas se siguen festejando, e incluso se han incorporado nuevas celebraciones, como por ejemplo el "Día del Pescado Frito", los recuerdos de nuestras entrevistadas hablan de una comunidad que en el pasado era muy organizada, entusiasta, con un gran sentido de pertenencia. 


\section{Imagen 1}

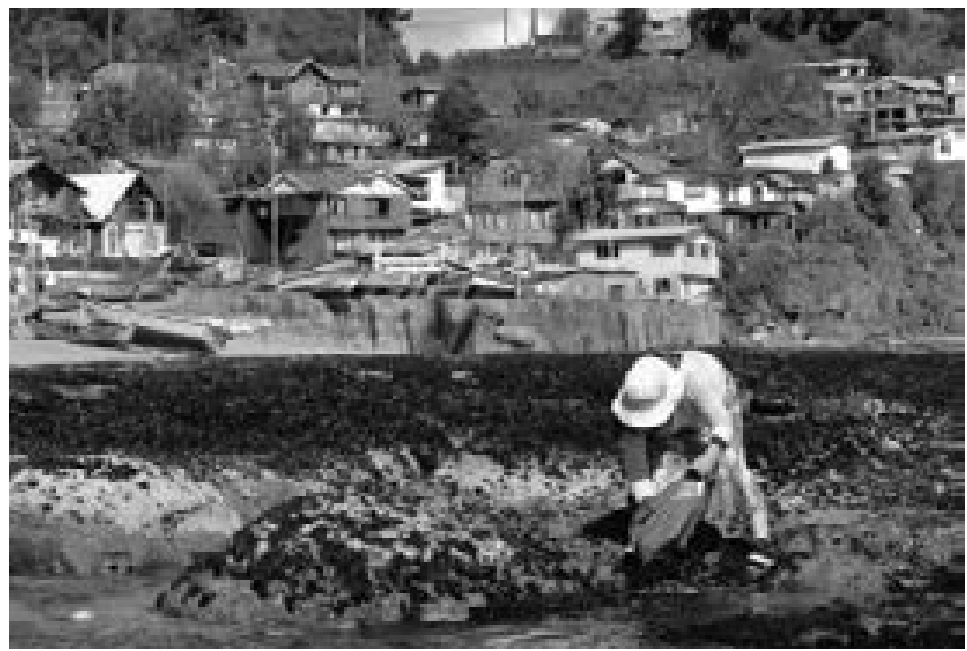

Alguera de Coliumo (fotografía tomada por el equipo de investigación)

En el caso de Coliumo, las entrevistas relatan que hace dos generaciones atrás era una localidad con pocos habitantes "cinco o seis familias", y que se fue poblando progresivamente a medida que estas familias aumentaban su descendencia. Las entrevistadas indican también que posteriormente al terremoto del año 2010 llegaron nuevas familias a vivir a la localidad, al parecer aprovechando los beneficios de la reconstrucción y por "necesidad". De esta manera, en la actualidad Coliumo tendría una mayor población de afuerinos que no necesariamente provienen de las familias pescadoras que poblaron esta parte del borde costero inicialmente.

En general, en los relatos de las entrevistadas afloran los recuerdos felices del pasado. Señalan que Coliumo era una zona abundante en recursos pesqueros, peces, algas, mariscos, que permitían a sus habitantes sobrevivir el día a día y echar mano a la recolección para la venta de productos, y la compra de los alimentos y productos necesarios para su sobrevivencia o bien para asegurar directamente la alimentación de la familia. Se mencionan productos como el pejerrey (Basilichthysaustralis), la merluza (Merlucciusgayigayi), el ulte (Durvilleaantarctica), la pancora (AeglaPlatensis), los caracoles (Phorcuslineatus) que existían en abundancia en el sector.

"Mi infancia fue hermosa. Yo soy recolectora y pescadora artesanal. Pescadora... artesanal eh salía con mi papá a la pesca, al congrio, a la corvina, a la jaiba a todo, todo lo que podía ser. Trabajé muchos años con mi padre en la pesca, llegué hasta Itata. Ehh dormí en la mar, en bote, yo creo que fui una de las primeras mujeres de Coliumo que, de la edad de la generación mía que salió a trabajar afuera, yo creo que la más que trabajó más" (Marcela).

Estos recuerdos positivos, de abundancia y vida en comunidad, contrastan también con recuerdos de períodos de grandes carencias, en que no existían condiciones básicas de salubridad y la caleta se encontraba muy aislada. 


\section{El trabajo de la recolección de algas}

Como se ha constatado en otros estudios etnográficos en la zona (Arteaga, 2012; Barriga \& Vergara, 2013), la recolección es una actividad económica que se ha transmitido de generación en generación, genera recursos a las familias y constituye un espacio de socialización, educación y de recreación para muchas personas. En general, son las mujeres quienes lideran esta actividad, pero es importante recalcar que es de carácter colectivo y familiar y que está determinada por los ciclos de la naturaleza.

\section{Imagen 2}

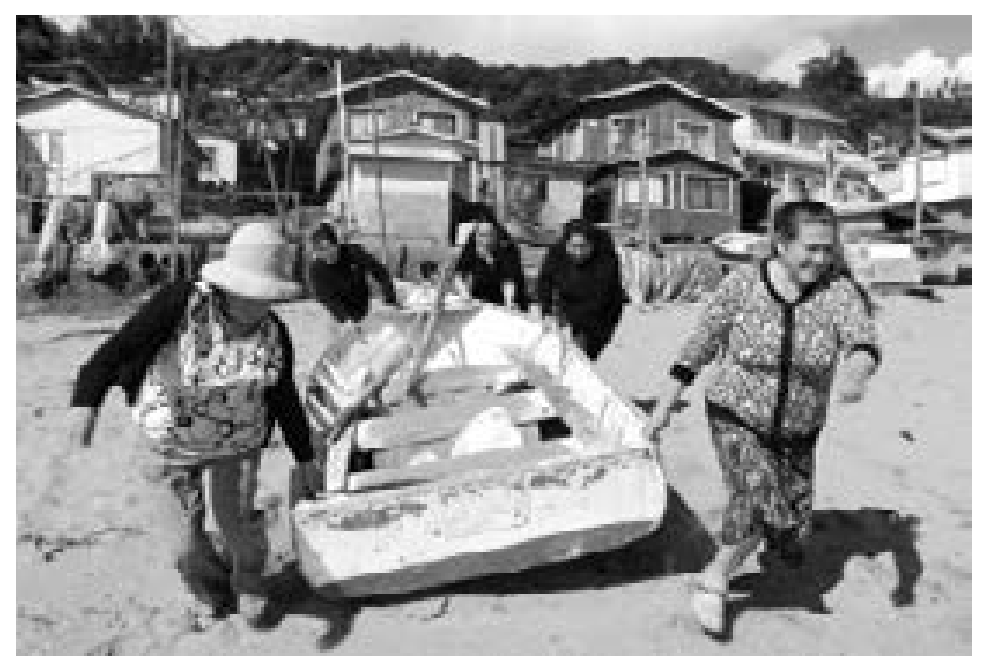

Algueras de Cocholgüe

(fotografía tomada por el equipo de investigación)

En el caso de ambas caletas la recolección de algas se considera una actividad casi exclusiva de las mujeres, aunque también hay varones que la practican, especialmente buzos, la actividad incluye a diferentes generaciones, niñas pequeñas, adultas y ancianas. La extracción se realiza principalmente entre los meses de septiembre y marzo, ya que es en esta época donde es posible secar el alga para su posterior venta.

En el invierno el alga que se recolecta y prepara es el luche. Este se cuece y se vende en bolsas pequeñas. La forma más común de comerlo es acompañado de papas, arroz o sopaipillas.
Las algas que se extraen en primavera $y$ verano son la luga, corta y larga, el pelillo y la cuchara. El proceso de extracción es variable, puede ser una recolección manual en la orilla de la playa y entre las piedras, se puede recolectar con "rastrillo" que consiste en lanzar una herramienta al mar que logra capturar las algas que luego se sacan a la orilla y, en algunos casos, también se puede recolectar de manera submarina con equipos especializados. En Cocholgüe la extracción es principalmente de orilla mientras que en Coliumo era frecuente el uso del rastrillo, aunque ahora se ha dejado de lado debido a la recomendación de expertos que señalan que el 
uso de este implemento provoca un daño a la sustentabilidad del alga.

La faena de recolección comienza a las 4 de la mañana, cuando un grupo de mujeres y familias se dirigen a la playa. En el caso de Cocholgüe hay distintos lugares de recolección; dependiendo del ánimo y del tiempo disponible para la actividad se elige el lugar de trabajo, eventualmente se hacen acuerdos como por ejemplo "sacar a medias", trabajar en parejas, etc.

Para empezar hay que esperar "la baja" que es cuando el mar está quieto y recogido, esto sucede dos veces al día, la primera vez muy temprano en la madrugada, y la segunda vez en la tarde, dependiendo de los ciclos de la luna y de las estaciones del año. Esta labor requiere de un conocimiento profundo de los ciclos de la naturaleza y además del recurso que se extrae, ya que hay que discernir entre los tipos de algas y el estado de maduración que estas tienen. De esto dependerá la posterior venta. Cabe destacar la relación de los habitantes con el mar y lo internalizado que tienen sus conocimientos sobre el comportamiento del mar en su caleta.

Respecto a la comercialización del recurso, la transacción se hace con un intermediario que luego vende o exporta el alga. Este personaje es conocido tanto en el mar como en el campo como el "cachencho", que generalmente, compra los productos a un precio mucho menor que el precio de venta. Ellos son quienes se acercan a las caletas para comprar y fijan el precio dependiendo de la calidad del alga, es decir, de lo limpia que esté, de la cantidad de arena que traiga y del tamaño, entre otras cosas. El precio actual del kilo de luga seca es de $\$ 500$ por kilo. El alga, luego de pasar por el comprador, es exportada a países como Japón donde se usa en la industria del plástico y de los cosméticos.

La mayoría de las entrevistadas se iniciaron como recolectoras desde muy niñas y aprendieron cuando acompañaban a sus madres a la faena. Es un trabajo que aporta directamente a la economía del hogar, y como se desarroIla entre primavera y verano se destina, generalmente, a la compra de útiles escolares y de alimentos no perecibles para el invierno (aceite, azúcar, harina).

El trabajo de la recolección implica un conocimiento profundo del territorio, de las zonas donde llega más el alga, de los accidentes geográficos de las orillas de las playas, de los caminos que permiten llegar a las zonas de extracción, etc.

Desde pequeños niños y niñas asisten a la luga, y al interior de las familias se promueve el trabajo de los niños y niñas como una manera de que ellos generen sus propios recursos que les permitirán comprar materiales escolares, juguetes y alimentos de verano (pelotas de playa, helados, etc.) Para los niños el trabajo se vuelve un juego, lo hacen en la mar, durante el verano, junto a sus familias. De esa forma describen las socias este fenómeno.

Para las algueras la recolección es también diversión, compartir, conectarse con su territorio, con su familia, tener un espacio de reflexión. Algunas recolectoras nos cuentan que mientras se recoge el alga en la orilla ellas se desconectan de su vida cotidiana y piensan en cosas distintas. Se encuentran también con sus pares, ya que generalmente la actividad se realiza en parejas o grupos, aunque varias mujeres también la practican solas. 
La independencia laboral también es algo que valoran, porque en este trabajo no se tiene patrones ni supervisores, cada una administra su tiempo y recursos.

\begin{abstract}
"A mí me gusta el mar, me gusta estar abajo del mar, a mí me relaja. Antes de que pasara esto del veintisiete de febrero, el terremoto, yo si tenía que ir a la luga sola yo me perdía pa... abajo de la caleta, cuando vivía en la caleta en mi casa, yo iba bajaba de kilómetro más kilómetros pero sola en la playa, sola, buscando luga, me quedaba sentada y toda la cosa. Y... me gustó la pega de la luga, me gustó. Es la pega que a mí me... me fascina, a mí me gusta el mar" (Guillermina).
\end{abstract}

Entre los aspectos negativos de este oficio se encuentran los problemas de salud que pueden desarrollar las recolectoras. Reumatismos, resfríos crónicos, problemas la espalda, lumbagos y escoliosis, artritis, sinusitis, entre muchas otras, todas como resultado de la larga exposición en las aguas frías y de las constantes fuerzas que tienen que hacer para transportar el alga, ya que en la caleta no existe ningún tipo de instalación para acarrear o apilar los sacos de alga que se juntan por jornada.

Por su parte, las entrevistadas de Coliumo también relatan que aprendieron el arte de la recolección de algas, observando a sus madres. Desde muy pequeñas junto a sus hermanos y/o hermanas jugaban a la orilla del mar, mientras sus madres recolectaban algas o mariscos. Con el tiempo se iban haciendo más participes de los procesos de la extracción de mariscos o algas a medida que crecían. Recuerdan la primera extracción propia como aquel día en que vendieron algas y pudieron comprar por primera vez algo anhelado como niñas.

En Coliumo la recolección de algas se puede realizar en la orilla del mar; principalmente en los "rincones" que son vértices con muchas rocas en donde golpean las olas constantemente. $O$ en las profundidades del mar y en formaciones rocosas dentro del mar. Las especies de algas que se recolectan son pelillo (gracilaria chilensis), chicoria (Chondracanthus chamissoi), luga roja (Gigartina skottsbergii) y luga negra (Sarcothalia crispata). El pelillo se encuentra disponible todo el año para su extracción. La chicoria y la luga, por su parte, se encuentran disponibles para la extracción principalmente entre primavera y verano, cuando alcanzan su mayor tamaño. Desde primavera hasta entrado el otoño, se trabaja intensamente en las caletas para guardar dinero para el invierno, cuando el clima hace más difícil la recolección debido a las intensas Iluvias. Estas algas son principalmente exportadas a países asiáticos, donde se utilizan en la preparación de comida y también para uso cosmético.

Las algas crecen aferradas firmemente a la roca, para su extracción se utiliza ancestralmente "el rastrillo", que consiste en una vara de madera (eucaliptus) vertical y otra horizontal con clavos, que arrancan el alga de las rocas o se puede usar la mano. Cuando la extracción es en las profundidades del mar se debe realizar buceando. El sindicato № 1 de Algueras de Coliumo extrae actualmente las algas de sus tres áreas de manejo con la ayuda de un buzo, quien obtiene el $50 \%$ de la ganancia de lo que extrae y el otro $50 \%$ es para el Sindicato, y se reparte entre todas las mujeres que integran el mismo.

A medida que se va recolectando el alga se va tendiendo y apilando sobre la arena para secarla, luego se guarda en sacos y se lleva a casa, donde se lava y se vuelve a tender para que se seque, luego para venderla hay que volver a mojarla. 
El luche, cochayuyo y los mariscos son comercializados en Tomé o Dichato. El luche se extrae, se lava, se cocina y se vende caliente, para ello se coloca dentro de bolsas de plástico y es envuelto en manteles para mantener el calor. El cochayuyo y los mariscos se venden crudos, pero en general, estos últimos son usados para la alimentación de la familia, ello debido a que la población de mariscos ha decrecido mucho en los últimos años, así como también el número de especies. Las habitantes de la caleta sostienen que antes existían muchas variedades de mariscos y peces que hoy han disminuido en cantidad o simplemente han desaparecido. El fenómeno de la desaparición de especies está muy presente en la consciencia de las habitantes de la caleta, la sobreexplotación de los recursos marinos sería la principal causa, señalando que luego del maremoto que removió todo el suelo marino, esta condición se agudizó.

La actividad de recolección es una actividad realizada constantemente en el tiempo por las mujeres, pero que involucra a toda la familia, pues en tiempos de escasez de pesca o de algún apuro económico se recurre al alga para incrementar los ingresos económicos de las familias. Nuestras entrevistadas señalaban que el alga "sirve para parar la olla".

Para reconocer el momento y lugar de donde recolectar el alga, las mujeres deben tener un vasto conocimiento de las mareas y la influencia de la luna en ellas, y los lugares propicios para la extracción, todo este conocimiento ha sido entregado por sus madres y padres y es transmitido de generación en generación.

\section{Las organizaciones sindicales}

El "Sindicato de Algueras, charqueadoras y mariscadoras de orilla de Cocholgüe" se fundó hace más de 20 años, desde hace 10 años su presidenta es la señora Guillermina Flores. Cuenta con alrededor de 300 socias, de las cuales la mitad participa activamente. Hay un grupo de ancianas que son socias vitalicias a las cuáles no se les exige participación, en cambio para el resto existe un protocolo establecido donde se encuentran los deberes y derechos de cada integrante. La asistencia a las reuniones mensuales, participación en proyectos, pago de cuotas son algunos de los asuntos que se han fijado para el funcionamiento y mantención de la organización en el tiempo. Muchas de las integrantes son familiares o tienen cierto grado de parentesco entre ellas, madres e hijas, hermanas, primas, cuñadas etc. La dinámica de las reuniones es familiar y existe gran confianza entre las integrantes que se expresa en las convocatorias, en donde las asistentes dejan de lado las formalidades para interactuar de manera relajada pues se sienten en un espacio de confianza, rodeadas por sus lazos de parentesco.

Los inicios del Sindicato de Algueras dan cuenta de distintos intentos por organizar formalmente a las mujeres de la caleta desde su rol como trabajadoras del mar. En un principio se formó un sindicato de mujeres que luego se fusionó con el Sindicato de Pescadores (espacio masculino), para finalmente constituirse de manera autónoma tal como se le conoce hoy en día.

\footnotetext{
"Empezamos años atrás... ¿cuánto... serán unos treinta años? Treinta, veinticinco años que nos juntábamos las mujeres allá donde la tía Juanita, todas las que fuimos la primeras del sindicato, o sea nos juntábamos porque éramos familia, primas, amigas, veci-
} 
nas y después ya con el tiempo nos hicimos sindicatos, igual que nuestros maridos o los otros pescadores, nos juntamos pero nosotras no más, sin hombres para armar el sindicato" (Guillermina).

Además del "Sindicato de Algueras, charqueadoras y mariscadoras de orilla de Cocholgüe", existen los siguientes grupos: Sindicato de trabajadores independientes de Pescadores de caleta Cocholgüe, Sindicato de Buzos, Mariscadores y Algueros de Cocholgüe, Sindicato de trabajadores independientes de Pescadores Artesanales, Armadores, Patrones y Tripulantes de la pesca artesanal y actividades conexas de la caleta de Cocholgüe.

A lo largo su historia el Sindicato de Algueras ha debido luchar y defender sus recursos $y$ territorios, exponiéndose incluso a situaciones de violencia, por ejemplo, el rapto de una de sus compañeras en la mar en manos de pescadores de otras caletas, mientras los encaraban por la extracción de los recursos que les correspondían. También han tenido conflictos con buzos y embarcaciones que han erosionado el lecho marino con prácticas de extracción que ellas consideran dañinas para las aguas de la caleta.

Durante años el sindicato de algueras de la caleta de Cocholgüe ha desarrollado diversos proyectos, actualmente su objetivo es la gestión de áreas de manejo para proteger y conservar los recursos marinos. El más reciente proyecto adjudicado consiste en la implementación de una cocinería que permitirá a las algueras producir nuevos ingresos.

Esta organización les brinda espacio para desarrollar no solo acciones políticas, también les permite crear instancias para la convivencia y el diálogo. El sindicato es una comunidad que permite a las mujeres de Cocholgüe desenvolver un rol activo en el quehacer de la caleta, una organización que las agrupa y realza su identidad como Algueras.

Por su parte, el Sindicato № 1 de Algueras de Coliumo se formó en el año 2000, pero es en el 2002 cuando se constituye legalmente. Su presidenta es la Señora Sara Garrido. Desde el año 2000 las mujeres recolectoras de la caleta comenzaron a organizarse para hacer frente a los buzos de Dichato, que luego de una fuerte crisis de merluza que se vivió por esos años, comenzaron a extraer algas desde el fondo marino de Coliumo, amenazando la disponibilidad de recursos y su actividad ancestral. En un principio se enfrentaron a los buzos y producto de ello recibieron insultos, golpes y muchos otros vejámenes. Entonces decidieron organizarse más formalmente y exigir a las autoridades una solución. El camino no fue fácil, tuvieron que enfrentarse a los buzos, se dieron cuenta que su trabajo no era reconocido como tal, a pesar de ser una tradición ancestral. Luego de una larga lucha que trajo enormes costos familiares para muchas de las mujeres que integraban el sindicato, lograron tener tres áreas protegidas. Si bien las áreas de manejo permitieron en gran medida terminar con los conflictos con los buzos de Dichato, se inauguró un nuevo período de conflictos internos al interior de la localidad de Coliumo por el control de los recursos marinos.

Las entrevistadas relatan que vivieron un período muy difícil para constituirse como sindicato, el que estuvo marcado por la persecución por parte de la comunidad, enfrentando amenazas incluso por parte de su propia familia: 
"Estuvimos momentos, años muy difíciles, muy complejos para la organización. Mujeres que llegaron a un extremo de ser amenazadas por sus propios esposos, que tenían que irse del sindicato porque los esposos habían sido amenazados por los armadores, que son los patrones de las embarcaciones (...) entonces eso lo encontrábamos súper injusto, lo encontrábamos súper denigrante para las mujeres para nosotras en particular, ahí hubo llanto, lloraban algunas, cuando teníamos reunión mentían, decían que iban a la iglesia católica a misa, y mentira porque iban a reunión del sindicato, yo tenía que hacer, tenía que hacer el... eh la reunión en la hora de la misa para que ellas dijeran que iban a misa y que no iban a reunión, te fijai. Mentía, pero ellas sentían que tenían que estar ahí" (Sara).

Asimismo, las entrevistadas relatan que posteriormente se vivieron nuevas divisiones en la comunidad, ya que el Sindicato № 1 se separa y se forma un segundo Sindicato de Algueras, lo que genera nuevas rivalidades entre las mujeres. Estos conflictos fueron producto de rencillas entre socias emparentadas entre sí (primas hermanas), ambas con un número de seguidoras que optaron por la división para generar propuestas independientes. Al parecer, la fuente principal de este conflicto es el control de los recursos a partir de las áreas de manejo. De esta manera, el segundo sindicato buscaba también establecer su propia área de manejo. Cabe señalar que estas divisiones se mantienen hasta la actualidad, existiendo todavía una palpable rivalidad entre ambos sindicatos. Esta división aparentemente ha repercutido en la cohesión del sindicato de Algueras № 1 Coliumo donde muchas de sus integrantes también cuestionan su rol actual y futura pertenencia a la organización.

Sin embargo, en relación a la existencia del Sindicato de Algueras № 1, las entrevistadas valoran especialmente -a pesar de las dificulta- des y conflictos- el hecho de que la existencia del sindicato les permitió recibir ayuda directa con posterioridad al terremoto del año 2010, por lo que sintieron que los esfuerzos y los problemas que atravesaron fueron en parte recompensados. Asimismo, el sindicato constituye un espacio de convivencia y apoyo, en que las mujeres actualizan su pertenencia a la comunidad. En suma, constatamos la existencia de agrupaciones sindicales que han surgido como una necesidad de las habitantes de ambas caletas para crear un espacio de poder, que convoque a las mujeres a actuar unidas; en Cocholgüe existe un único sindicato compuesto exclusivamente por mujeres con un núcleo férreo basado en la convivencia y dinámica familiar, a diferencia de Coliumo donde el sindicato original se fragmentó en dos debido a conflictos entre sus integrantes, los que actualmente aún persisten.

\section{Economía Local y Perspectivas Futuras}

En la Caleta Grande de Cocholgüe la actividad económica central es la pesca. En palabras de las entrevistadas "es la caleta merlucera más grande de Chile", que quiere decir que es la caleta desde donde se extrae la mayor cantidad de este recurso. Debido a que en Cocholgüe no existe muelle, el desembarque de los recursos extraídos desde el mar se realiza en caletas cercanas como Coliumo y Tumbes, es por esto que no hay un registro de lo que producen las familias de Cocholgüe en el contexto de la pesca artesanal. Esta actividad generalmente requiere de la asociación entre miembros de una misma familia (padre e hijo, primos, hermanos, esposo y esposa), tanto como para la compra de insumos y herramientas (mallas, botes), como para su ejecución. 
La rutina de la pesca implica salidas en la madrugada, trabajo durante días, faena y venta del pescado, mantención de los implementos (carpintería de ribera, remienda de mallas, etc.), entre otras cosas. En la Caleta Grande y en la población se puede observar a distintas horas del día a hombres remendando sus mallas.

En las entrevistas, la mayoría de las mujeres se definen también como pescadoras, poseen tarjetas de pesca (permiso necesario para salir a la mar a realizar esta actividad) y han realizado esta actividad desde niñas, al interior de sus familias y luego de adultas junto con sus esposos. En la mayoría de los casos la pesca estuvo más presente cuando en sus biografías ellas se encontraban formando familia, en plena crianza de sus hijos/as pequeños/as, cuando estaban construyendo sus casas, independizándose de los padres, etc.

También se mencionan casos de mujeres de la caleta que tienen toda una trayectoria en las artes de la pesca y que son reconocidas como pescadoras "netas" tanto por su talento como porque realizan esta actividad de manera independiente de los varones.

Otra actividad propia de la vida en el mar que se realiza en Cocholgüe, es la elaboración de pescado seco. Es un proceso largo que comienza con la limpieza del pescado, luego se abre, se mete en alambres y se tiende al sol. El pescado debe guardarse en la noche y moverse durante el día para que le llegue sol y ventilación a todas partes. Luego de tres días colgados se deja tres días más arriba del techo de una vivienda para terminar con el secado. Su comercialización se realiza al interior de la comunidad y en ferias de Tomé.
La recolección de mariscos beneficia directamente la cocina familiar, no es común su comercialización, aunque hay quienes lo van limpiando, envasando y congelando para venderlo a personas cercanas. La captura de crustáceos también es parte de las múltiples actividades económicas ligadas al borde costero y en Cocholgüe hay mujeres que trabajan la jaiba. Para ello, instalan trampas en el mar, tipo jaulas, que luego retiran con el producto. El proceso incluye la cocción y venta del producto listo para consumir o simplemente la comercialización de la jaiba viva en ferias de Tomé.

Uno de los principales lugares de venta para las mujeres del sindicato y sus familias es la llamada "Emplanada" de Tomé. Este lugar es un punto de venta de productos del mar frescos, y también existen allí varias cocinerías cuya especialidad son los mariscos y pescados. Hace décadas los botes llegaban directamente desde la caleta hasta este punto a descargar la pesca. Ahora, generalmente los productos que venden tienen un proceso previo, por ejemplo el pescado se limpia y filetea, los mariscos se limpian y envasan, es por esto que las mujeres que realizan esta labor en sus casas llegan por tierra a este sector de la costa de Tomé.

Desde el año 2006, las caletas comienzan a vivir la crisis de la merluza, esta crisis es atribuida al impacto generado por la pesca de arrastre en las aguas de la zona y afecta principalmente a las familias dedicadas a la pesca artesanal, quienes no poseen medios ni autorizaciones para adentrase en el mar más allá de los límites establecidos en la ley, a saber:

\footnotetext{
“(...) el Artículo 47 de la Ley General de Pesca y Acuicultura, establece que se reserva a la pesca artesanal el ejercicio de las actividades pesqueras extractivas
} 
en una franja del mar territorial de cinco millas marinas medidas desde las líneas de base normales, a partir del límite norte de la República y hasta el paralelo 4325'42" de latitud sur, y alrededor de las islas oceánicas”.2.

La coexistencia de la pesca artesanal e industrial en las costas de Chile y del territorio en estudio, tiene como consecuencia la precarización de este oficio ancestral, que en la actualidad no satisface por sí solo las necesidades de las familias. En este contexto, la asignación de "cuotas" para la pesca artesanal aparece como una medida no acorde a la realidad de las caletas y al ejercicio de la pesca. En efecto esta situación se interpreta como una injusticia en comparación con las licencias atribuidas a la industria pesquera.

Las mujeres y pescadores señalan a la grandes pesqueras como responsables del deterioro de los recursos marinos, debido a la extracción intensiva e indiscriminada que las grandes embarcaciones realizan dañando el fondo marino y arrastrando en sus redes a todas las especies que se crucen en el camino de la red, dando a su vez muerte a la biodiversidad de la zona.

En respuesta a esta crisis surgen los empleos de emergencia que lograron mitigar la escasez de recursos para la familias, actividades de aseo y mantención de la zona son los empleos que desarrollan las mujeres de la caleta insertadas en la iniciativa de "Inversión y Mejoramiento de la Comunidad" del SENCE; iniciativa que apuntaba inicialmente a los varones de la localidad quienes rechazaron la propuesta para seguir dedicándose la mayor parte del tiempo a la pesca artesanal. Sin embargo, esta iniciativa de mitigación no logra aportar a dar solución a la situación de crisis de la pesca artesanal, pues es una medida compensatoria que no tiene posibilidades de dialogar con el actor que las propias comunidades han identificado como responsable de la crisis en sus caletas: la industria pesquera. Existe por tanto un problema político, económico y social que no está siendo abordado desde la política pública estatal en su origen, por lo tanto la proyección de este tipo de soluciones no corresponde con las expectativas que tienen las familias de seguir ligadas al mar como fuente de sus actividades económicas y como elemento que configura sus identidades colectivas y territoriales.

En el año 2010, luego del terremoto y tsunami que afectó las costas del país el 27 de febrero, la situación se vuelve más compleja pues los efectos devastadores del mar desestabilizaron a las familias de Cocholgüe y Coliumo quienes perdieron sus instrumentos de trabajo, embarcaciones, redes, trampas, motores etc. Siendo en Coliumo, sus hogares también parte importante de las pérdidas.

Así, en la actualidad y desde hace varios años, la actividad económica complementaria más común y permanente es la participación en el Programa Proempleo. Hoy en día gran parte de las recolectoras organizadas en el sindicato trabajan bajo esta modalidad. La jornada de trabajo es de lunes a viernes, jornada completa. Los trabajos que realizan responden a las necesidades de la comunidad y del entorno, como por ejemplo, limpieza de playa y calles, mantención de las sedes sociales, etc. Esto se complementa con espacios de talleres grupales, principalmente de manualidades y oficios.

Este componente de la economía local define en la actualidad varias de las dinámicas de la caleta, como por ejemplo, las posibilidades de 
las que mujeres trabajen en el mar. Hoy en día la recolección se sigue realizando en las estaciones que corresponde, principalmente los fines de semana que es cuando están liberadas del trabajo en el Programa Proempleo. La vida en comunidad también está íntimamente ligada con esta actividad ya que la metodología de trabajo es en cuadrillas, tanto en los talleres como en las actividades laborales.

Por su parte, en el caso de Coliumo constatamos un progresivo abandono de las actividades de pesca y recolección. Esto ha sido fuertemente motivado por la crisis de escasez de productos que se experimenta desde hace varios años. Coliumo hoy en día se plantea un escenario de transformación. Frente a la crisis que enfrentan las actividades de recolección y pesca, sus habitantes se plantean nuevas perspectivas. Quienes mantienen el apego con su territorio ven en el turismo posibilidades de mantener la subsistencia de localidad, por lo que han realizado cursos, capacitaciones y proyectan nuevos emprendimientos con la finalidad de atraer turistas y generar nuevas fuentes de ingreso a partir de esta actividad. Por otro lado, las mujeres constatan que en las nuevas generaciones está el deseo de continuar estudios superiores y abandonar Coliumo para realizar otras actividades económicas. Esto en gran medida como reacción frente a las duras condiciones del trabajo en el mar (con sus considerables repercusiones en el largo plazo en la salud de las mujeres) y a la crisis productiva que enfrenta Coliumo en la actualidad.

\footnotetext{
"Ponte yo tengo artrosis declará, tendinitis igual, el hombro y mis manos. Es por lo mismo, o sea, tu llegai (a médico) te dice, ya tú trabajaste, ahora tienes los resultados poh hija. Tu eres una mujer muy sacrificada entonces, la juventud de ahora no, ellos tuvieron la Universidad, así la mayoría de las hijas de mi hermana estudia-
}

ron en la Universidad, profesionales y chao, se fueron de la caleta y ya no quieren ser pescadores" (Marcia).

Sin embargo, el abandono de las actividades pesqueras por parte de las nuevas generaciones, contrasta con el sentimiento de apego hacia el mar y hacia las actividades marinas que tienen las mujeres de mayor edad, que dicen que las impulsa a continuar vinculadas al mar a pesar de las dificultades.

"Yo voy a buscar luche y yo lo vendo aquí en mi propia aldea. Yo salgo a vender, yo lo voy a buscar, yo lo lavo, yo lo limpio, lo coso y lo saco a vender, y yo me gano mis productos. Voy a mariscar, vendo tacitas, los caracoles, yo no dejo mi rubro porque estoy acá arriba me queda más lejos, tengo que pagar bus en bajar o bajo al cerro y voy a buscar mi producto y vendo. Compro pescado y vendo, porque tú lo llevai como en la sangre no sé, es que no te lo podi [sic] sacar. Porque yo he tratado ponte yo tengo una pega ahora que es por el Gobierno, los pro empleo y yo pero yo igual echo de menos la mar poh yo echo de menos ir a mariscar ponte. No hallo la hora que día sábado que tengo libre voy a mariscar, es una cosa que llevai, una cosa que te tira" (Marcela).

\section{Relaciones de género en la Caleta}

Uno de los aspectos en que nos interesaba indagar especialmente en la investigación etnográfica, tiene que ver con las relaciones de género. Al consultar a las mujeres algueras respecto a sus relaciones con los hombres en el pasado y el presente, tienden a referirse al pasado como un período en el que existía "mucho machismo" y en donde las mujeres estaban obligadas a obedecer a los hombres, primero a sus padres y posteriormente a sus maridos. Asimismo, las mujeres señalan que su matrimonio marca un antes y después en términos de su relación con las actividades costeras. 
El matrimonio para muchas de estas mujeres marca un precedente que define su participación en las labores costeras. Luego de casarse con pescadores artesanales, las mujeres que no pertenecían a la caleta de Cocholgüe o Coliumo comenzaron a asentarse en la localidad familiarizándose gradualmente con la vida en la costa y los trabajos de recolección, para convertirse con el tiempo en experimentadas algueras y mariscadoras.

Ser madre, esposa, alguera, mariscadora y pescadora artesanal eran las actividades que debían complementar muchas de las mujeres que habitaron la caleta, en su diario vivir. Cuando las familias estaban compuestas por muchos hijos, las mujeres que acompañaban a sus maridos en la pesca debían madrugar dejando el cuidado de los más pequeños a sus hermanos mayores, si estos no tenían edad suficiente para laborar mar adentro.

En múltiples entrevistas nos contaron de situaciones en las que mujeres con hijos recién nacidos, que no contaban con redes de apoyo familiares, debían embarcarse para realizar labores mar adentro dejando a sus pequeños solos durante la noche, debido a la necesidad de trabajar por el bien de la familia.

Luego de acabar la jornada de pesca donde las parejas lanzan sus redes a las aguas, las mujeres debían volver a su hogar tras cuatro horas aproximadas de ausencia para intentar descansar un par de horas y continuar con las labores domésticas, cocina, compras y otras actividades propias de la crianza y educación de sus hijos. El temor de muchas mujeres que debía abandonar su hogar durante las oscuras noches en la caleta, era volver a casa y encontrarse con problemas, accidentes o desgracias ocurridas a sus hijos durante su ausencia como por ejemplo que los recién nacidos se ahogasen, que despertaran sin alguien que pudiese consolarlos o que cualquier evento desafortunado les ocurriese a sus hogares mientras estaban lejos. Además el miedo de las pescadoras no solo se limitaba a los problemas que ocurriesen en casa, pues adentrarse a la mar es una labor peligrosa y no volver nunca a tierra también es una posibilidad dentro del oficio, como ha ocurrido con muchos pescadores artesanales que han perdido su vida trabajando en el mar.

En el caso de Coliumo las entrevistadas señalan que antiguamente era común que las mujeres se embarcaran en las duras actividades de la pesca en igualdad de condiciones con los hombres. Si bien se trataba de un trabajo duro y sacrificado, las necesidades lo exigían. Asimismo, indican que las mujeres además de trabajar directamente en la pesca, tenían el recurso de la recolección y venta de algas. Las entrevistadas destacan que para estas actividades se necesitaba mucha fuerza y valentía:

"Una mujer que tenga que ser bien aperrada al mar porque, se necesita fuerza. $\mathrm{Pa}^{\prime}$ todo, desde que topó el bote, porque si no anda en bote no puede. Tiene que ir a andar en bote o si va a sacar así por la orilla tiene que... con un saco, mover saco, o si va a sacar marisco, mover piedra. Tiene que ser una, no puede ser una persona que no tenga... fuerza" (Minerva).

Así, las mujeres realizan labores en la pesca como una forma de incrementar sus ingresos y ganar autonomía económica. Las entrevistadas que se dedicaron a la pesca relatan que el trabajo en el mar las hacía sentirse fuertes y capaces, un sentimiento que se complementaba con la satisfacción de los buenos ingresos obtenidos: "yo tuve mucho más con mi compa- 
ñera, uuhh mucho, mucho más, entonces nos sentimos las mujeres más valiosas poh, porque igual podíamos hacerlo..." (Minerva).

Asimismo, señalan que la vida de las esposas de pescadores en la costa también requería de tareas pesadas, levantarse en la madrugada a recolectar luga, regresar a la casa a hacer el fogón, calentar agua y preparar la comida que debía estar lista a las 8 de la mañana cuando los pescadores regresaban de la pesca luego de ir a Dichato a vender sus productos. Estas tareas incluían también el charqueo del pescado lo que era un trabajo pesado en tiempos de abundancia de pescado, especialmente de la merluza. Las mujeres usaban entonces su ingenio para combinar estas labores con el cuidado y crianza de sus hijos e hijas:

"Mi mamá a mí me contaba, y mi hermana, que por ser a mí, me crió en una jaba. De estas jabas de, de tomate no sé, y dice que tiene un cordel laaargo dice por allá, y cuando a veces escuchaba que yo lloraba, me movía un cordelito para que yo me quedara calladita. Así dijo que me había criado" (Minerva).

Asimismo, las entrevistadas relatan que frente a la necesidad económica ellas siempre echaron mano a otras actividades, como la venta de alimentos preparados o el trabajo esporádico como empleadas domésticas, como una forma de aumentar el exiguo presupuesto familiar. Se trata de un período en que había pocas oportunidades para las mujeres, donde lo que se esperaba era que se casaran y no existía la expectativa de continuar la educación. Las mujeres se desempeñaban principalmente como dueñas de casa y eran responsables de la crianza de los hijos y trabajaban en la recolección de algas y otras labores esporádicas:
"Y resulta de que hasta ahí no más dejé mis estudios porque me casé, porque en realidad, nadie te dijo tienes que seguir estudiando. Es como que te casaste y, te casaste y ahora eres dueña de casa. Mi marido se fue a trabajar afuera entonces yo quedé como dueña de casa no más. Después de dos, tres años tuve a mi hija y seguí mi rubro no ma de dueña de casa, de mamá, trabajando en el mar, las algas, mariscos todas esas cosas... de empleá cuando se podía hacer, cuando yo podía dejar a mi hija con alguien, cuando podía quedarse mi mamá, mi suegra, eso. Pero después de todos esos años, a los veintisiete años, ahí empecé de nuevo, retomé mis estudios". (Minerva).

Así, vemos que las relaciones de género están marcadas en el pasado por un fuerte control masculino. Las mujeres asumen roles importantes en las actividades productivas, sin que ello implique abandonar las responsabilidades domésticas históricamente asignadas a ellas. Así podríamos hablar de la existencia de una doble jornada, que parece estar marcada por un continuo en donde los límites entre ambas esferas no tienen la claridad que presentan muchas veces los contextos urbanos. En este caso, se trata de un continuo deambular entre el trabajo remunerado y la casa, recolección y secado de algas, la preparación de alimentos para la casa y la venta. Si bien las mujeres definen estas actividades como un intenso trabajo, al mismo tiempo, indican que sienten la satisfacción de haber "criado bien a sus hijos" y de haber luchado para que en su casa "no faltara nada".

De esta manera, su participación en la producción y economía local es algo que ellas reconocen y valoran de sí mismas. Ahora bien, los cambios ocurridos en los últimos años, que llevan a una crisis en la producción pesquera, hacen que las mujeres asuman un nuevo rol en la economía familiar, al ser las "proveedoras estables" a partir de sus ingresos en el Programa ProEmpleo. Es interesante notar 
que esta oportunidad surge precisamente del rechazo a este programa por parte de los varones de la Caleta, quienes no estuvieron dispuestos a involucrarse en actividades que implicaran "aseo y ornato" de los espacios públicos. Las mujeres toman esta oportunidad y la transforman en un espacio propio, en que trabajan, se reúnen con sus compañeras y organizan actividades comunitarias. En ese sentido, si bien en términos simbólicos se sigue relevando la figura del "marido-pescador-proveedor" en la práctica las mujeres reconocen que son ellas quienes aseguran el sustento de sus familias y el contar con recursos básicos, especialmente en los duros meses de invierno. Por lo tanto, concluimos que en este espacio existe una ambigüedad en lo que se refiere a definir las relaciones de género. Por una parte, las mujeres parecen todavía referir a una "autoridad masculina", hablan de "pedirle permiso al marido" y la necesidad de cumplir con sus "obligaciones en la casa", pero al mismo tiempo parecen disfrutar de cierta autonomía y libertad de acción. Se trata, por lo tanto, de relaciones marcadas al mismo tiempo por la cooperación y el conflicto (Agarwal, 1997). Las algueras hacen notar la existencia de un pasado en que hombres y mujeres trabajaban a la par en las actividades marítimas y señalando que hoy en día además se da un cambio en las nuevas generaciones en que las mujeres tienen un mayor espacio de decisión y posibilidades de realización más allá del ámbito doméstico.

\section{Conclusiones}

El objetivo de este proyecto era indagar en los saberes y labores ligadas a actividades productivas del borde costero, realizadas por mujeres y su relación con la configuración de identidades locales en las caletas de Cocholgüe y Coliumo durante el año 2015.

A través del método etnográfico se realizó el acercamiento a la comunidad de mujeres contemplando actividades como la conversación casual, la observación participante y no participante, y las entrevistas en profundidad.

A través de esta investigación se logró caracterizar las actividades que realizan las mujeres en el borde costero y cómo su identidad de género se ve configurada por dichas actividades y las tareas que asumen en el ámbito doméstico y reproductivo. En ese sentido, constatamos la complejidad de la construcción del género en que los roles, conceptos normativos, instituciones e identidad subjetiva no pueden ser disociados (Scott, 1990).

En ambas localidades se relatan los inicios del poblamiento en vinculación a las actividades del borde costero, y se da cuenta de un período de abundancia de recursos en que las actividades eran múltiples y era posible la subsistencia de las familias en torno al mar. Este período es descrito también como una época de grandes sacrificios, en que no existían las comodidades modernas y el aislamiento geográfico de ambas caletas era mucho mayor, lo que hacía más difícil la comercialización y compra de productos de primera necesidad.

En el ámbito de las relaciones de género, las entrevistadas describen el pasado como un período en el que las mujeres trabajaban a la par con los hombres, en donde era común que ellas salieran a pescar y realizaran actividades como remar, pescar con red y bucear. Estas actividades les permitían tener una cierta autonomía económica y acceder a sus propios 
recursos económicos. Además de estas actividades, las mujeres señalan haber realizado tempranamente actividades de recolección de mariscos y algas, lo que les permitía solventar el día a día e incluso alimentar directamente a sus familias con los productos recolectados. De esta manera, el mar es visto como un proveedor siempre dispuesto a brindar algo, es una fuente permanente e inagotable de recursos. En tal sentido, constatamos la existencia de un continuo entre lo reproductivo-productivo en que ambas esferas no aparecen disociadas sino que más bien se complementan cotidianamente en las rutinas de las mujeres. Así, al analizar la relación entre construcción de género y economía, en el caso de las algueras (al igual como ocurre en las sociedades cazadoras-recolectoras) es necesario tener en cuenta que históricamente las mujeres han tenido un rol fundamental en la economía y en las actividades productivas, lo que persiste en la actualidad e incide en su posición al interior de la familia. En tal sentido, es necesario considerar que las relaciones de género, incluso cuando pueden estar marcadas por la subordinación de género pueden implicar también espacios de poder para las mujeres (Montecino \& Rebolledo, 1996; Mwaipopo, 2000).

Al mismo tiempo, las entrevistadas señalan que en el ámbito familiar y sexual las mujeres se enfrentaban a un fuerte conservadurismo y control por parte de los varones. Esto se reflejaba en que debían casarse tempranamente (una vez que su "pololeo" era de conocimiento público) y no podían continuar sus estudios. De esta manera, varias entrevistadas relatan que no terminaron sus estudios primarios o secundarios y se dedicaron tempranamente a la crianza de sus hijos. Por lo que su vida, parece estar marcada por las obligaciones domésticas y una serie de tareas cotidianas que debían ejecutar en torno a las actividades pesqueras de sus maridos, para asegurar de este modo la subsistencia de sus hogares.

Por otro lado, y en el período más reciente, este estudio da cuenta de un contexto de transformación en que el terremoto y tsunami del año 2010 marca un antes y un después. La pérdida de viviendas, implementos de trabajo, el desplazamiento hacia nuevas viviendas como producto de la reconstrucción son hechos que marcaron la vida de las mujeres entrevistadas. Esto va aparejado con una fuerte crisis en la explotación de los recursos marinos, que hace que los habitantes de ambas caletas -especialmente las mujeres- estén buscando nuevas fuentes de ingreso y por consiguiente abandonen sus actividades tradicionales de recolección de algas y mariscos. Este cambio es vivido con tensión por parte de las mujeres quienes todavía se sienten vinculadas fuertemente al mar. Sin embargo, el deterioro de su salud y de sus condiciones de vida las obliga a buscar nuevos horizontes.

En el caso de Cocholgüe constatamos que con la dinamización de la economía de las familias de las mujeres recolectoras de algas, propiciada por la influencia del turismo, la participación en el Programa Proempleo y nuevos proyectos, hay una menor dedicación a las labores de pesca y recolección en términos de tiempo. Sin embargo, proyectamos que en el mediano plazo este quehacer no se abandonará porque cumple una función específica en la economía familiar: ahorrar para comenzar un nuevo año, y además porque es una actividad que les reporta un gran sentido de pertenencia, un sentimiento identitario colectivo que cotidianamente se refuerza en la organización sindical. 
Por su parte, las mujeres de Coliumo se encuentran en el presente desarrollando nuevos proyectos productivos tales como una planta de secado y tratamiento de algas. Las algas serán comercializadas para la industria cosmética y serán usadas en la Cocinería del Sindicato que prontamente será inaugurada. De esta forma, las algueras buscan generar nuevos ingresos económicos manteniendo algunos elementos de sus actividades tradicionales.

Así, en este escenario de cambio, las posibilidades de desarrollo turístico de ambas caletas son vistas como una oportunidad para las mujeres, como una forma de mantener actividades tradicionales, por ejemplo, la comercialización de alimentos típicos de la zona a partir de la oferta de productos y servicios turísticos. De esta forma, en ambas caletas se han puesto en marcha proyectos que van en esa línea y las mujeres cifran sus esperanzas en estas iniciativas, como forma de poder mantener al menos parcialmente ciertos rasgos de su modo de vida tradicional e identidad cultural. Ello, en un escenario en que los y las jóvenes se van y buscan a través de los estudios superiores alcanzar nuevos horizontes de vida, abandonando las actividades pesqueras tradicionales.-

\section{Notas}

${ }^{1}$ El artículo corresponde a los resultados del proyecto de investigación "Las Mujeres y la Mar. Identidades vinculadas a actividades productivas en el borde costero de las caletas de Coliumo y Cocholgüe", ejecutado por el Programa Multidisciplinario de Estudios de Género de la Universidad de Concepción y que contó

\section{Referencias bibliográficas}

Agarwal, B. (1997). "Bargaining and Gender Relations: Within and Beyond the Household". Feminist Economics, Vol. 3, № 1.

Arteaga, L. (2012). Factores de género que influyen en el emprendimiento. Caso: algueras independientes Caleta Gente de Mar, Penco. (Memoria de Título de Antropología). Facultad de Ciencias Sociales, Universidad de Concepción, Chile.

Barriga, J. \& Vergara, V. (2013). "Construcción y relaciones de género en la producción pescador/alguera. El caso del sindicato de pescadoras y algueras de Coliumo". Ponencia presentada en XXIX Congreso de la Asociación Latinoamericana de Sociología, Santiago.

Montecino, S. \& Rebolledo, L. (1996). Conceptos de género y

\section{Otros documentos citados:}

Comuna de Tomé Atlas Identitario (2014). Disponible en: http:// www.portaltome.cl/images/01-Tome-atlasIdentitario-.pdf. Fecha de consulta: 12 de octubre de 2015. con el financiamiento del Museo de Historia Natural de Concepción y la DIBAM.

${ }^{2}$ Ley № 18.892 , de 1989 y sus modificaciones, Ley General de Pesca y Acuicultura.

desarrollo. Santiago: PIEG (Programa Interdisciplinario de Estudios de Género), Universidad de Chile.

Mwaipopo, R. (2000). "Gender and Power in the Use and Management of Coastal Space and Resources in Saadani Village, Tanzania". Bulletin de l'APAD, № 20 (puesto en línea el 5 de abril de 2006). Disponible en: http://apad.revues.org/252 Fecha de consulta: 30 de noviembre de 2015.

Scott, J. (1990). "El género, una categoría útil para el análisis histórico". En Amelang, J. S., \& Nash, M. (eds.). Historia y género: Las mujeres en la Europa Moderna y Contemporanea. Valencia: Edicions Alfons el Magnànim.
Plan de Reconstrucción del Borde Costero. Plan Maestro Coliumo. Intendencia Región del Bío-Bío, Diciembre de 2010. Disponible en: www.minvu.cl/incjs/download.aspx?glb_cod...PRBC\%20Coliumo. Fecha de consulta: 12 de noviembre de 2015. 